\title{
A Comparison of Short Sleep Duration and Insulin Resistance Association in Children Aged 13-15 Years Old and 16-18 Years Old
}

\author{
Claudia Magdalena Felisia Kurube ${ }^{1}$, Nur Aisiyah Widjaja ${ }^{1}$, Roedi Irawan ${ }^{1}$, I.G.M. Reza G. \\ Ranuh $^{1}$, Retno Asih Setyoningrum ${ }^{1}$, Hari Basuki ${ }^{2}$ \\ official email address: Claudia_felisia@yahoo.com
}

1Child Health Department, Medical Faculty, Universitas Airlangga/Dr. Soetomo General Hospital, Surabaya 60286-Indonesia 2Public Health Faculty, Universitas Airlangga, Surabaya 60286-Indonesia

\begin{abstract}
Background: Adolescents have unique sleep patterns and reduced sleep duration due to hormonal, activity, and environmental influences. Short sleep duration could be a factor in obesity, and insulin resistance might cause various metabolic problems. Several previous studies have conveyed different results. The present study analyzed the relationship between sleep duration and insulin resistance in obese adolescents with metabolic syndrome.
\end{abstract}

Methods: A total of 62 adolescents aged 13-15 years and 62 adolescents aged 16-18 years who met the criteria for metabolic syndrome based on the International Diabetes Federation 2007 from 12 secondary schools in Surabaya and Sidoarjo. Insulin resistance was determined using the Homeostatic Model Assessment for Insulin Resistance (HOMA-IR) with a cutoff value of $>3.54$. Sleep duration was determined based on direct interviews with research subjects and classified as short sleep duration when sleep duration was $<8$ hours. The obtained data were analyzed using Chi-Square, Mann-Whitney, and T-test (significant at $\mathrm{p}<0.05$ ).

Results: The subjects were dominated by male adolescents (67.7\%). There was a meaningful relationship between age and sleep duration $(\mathrm{p}=0.035)$. The 16-18 year age group had more short sleep duration. The results of the analysis showed that there was a relationship between short sleep duration and the incidence of insulin resistance in both age groups, in the 13-15 year age group (PR 1.78; phi coefficient 0.430; $\mathrm{p}<0.001$ ) and in the 16-18 year age group (PR 2.90; phi coefficient 0.478; $\mathrm{p}<0.001$ ).

Conclusion: Short sleep duration is associated with insulin resistance in obese adolescents with metabolic syndrome.

Keywords: insulin resistance; metabolic syndrome; obese adolescents; sleep duration.

\section{INTRODUCTION}

Sleep is a lifestyle component that is often overlooked but can be seen as an essential preventive measure, an indicator to assess a person's current health status or health outcomes that may lead to other health complications [1]. Sleep plays a role in determining health status. Children, adolescents, and adults control diurnal rhythms related to energy homeostasis [2]. Short sleep duration causes changes in levels of several hormones, including leptin, ghrelin, insulin, cortisol, and growth hormone, and increases sympathetic activity with elevated catecholamine levels. These hormonal changes and sympathetic activity lead to energy imbalance, overweight or obesity, and insulin resistance [3,4].

Healthy sleep requires sufficient duration, the right time, good quality, regularity, and the absence of sleep disturbances [5]. The National Sleep Foundation in the United States recommends that teens aged 14-17 get between 8 and 10 hours of sleep per night to maximize overall health and well-being. Longer sleep duration is associated with lower adiposity indicators, better emotional regulation, academic achievement, and better quality of life/well-being [6]. 
The prevalence of obesity in children and adolescents has increased almost worldwide in the last three decades, followed by an increase in comorbidities, especially metabolic syndrome [7,8,9]. The International Diabetes Foundation states that metabolic syndrome should not be diagnosed in children under ten years, but weight loss education should be provided to abdominal obesity. For children ten years of age or older, the metabolic syndrome can be diagnosed by abdominal obesity and the presence of two or more other clinical features (i.e., elevated triglycerides, low HDL cholesterol, high blood pressure, elevated plasma glucose). For children over 16 years, the IDF adult criteria can be used [10].

Several previous studies stated that short sleep duration was associated with insulin resistance and increased HOMAIR values [8,11]. However, a study in Indonesia did not find an association between sleep duration and the incidence of metabolic syndrome in adolescents, and a study by Sung et al. stated that shorter sleep duration did not predict the presence of metabolic syndrome, adiposity, or insulin resistance in children and obese adolescents [12,13]. There are pros and cons, and there is still a lack of studies on adolescents, so that this study will see whether there is a relationship between short sleep duration and insulin resistance, especially in the obese adolescent population with metabolic syndrome, especially in East Java.

\section{METHODS}

\subsection{Patient and methods}

The present study used an analytical observational research approach with a cross-sectional design. This study primary data taken from February to May 2020. The study was conducted in 12 junior and senior high schools in Sidoarjo, East Java, Indonesia. Subjects were determined by total sampling that met the inclusion and exclusion criteria. Inclusion criteria were obese adolescents aged 13-18 years who met the criteria for metabolic syndrome. In addition, the subject, along with his parents, voluntarily participated in this study. Children who have been diagnosed with diabetes mellitus or are taking anti-diabetic drugs will be excluded.

Metabolic syndrome was determined based on the 2007 international diabetic federation (IDF) metabolic syndrome criteria, namely waist circumference 90th percentile for age and sex accompanied by 2 of the following criteria: (a) fasting triglyceride level $150 \mathrm{mg} / \mathrm{dL}$, (b) HDL fasting HDL levels <40 mg/dL, (c) fasting blood sugar levels $100 \mathrm{mg} / \mathrm{dL}$, and (d) systolic blood pressure 130 or diastolic $85 \mathrm{mmHg}$ (Alberti, 2010). Blood pressure checks were carried out using a OneMed digital blood pressure measuring device. Blood pressure checks were performed in a sitting position after the subject had rested for 10 minutes.

Sleep duration was obtained through direct interviews. Subjects were asked to report their sleeping and waking hours each day for the last three days. Sleep duration is short if sleep duration is < 8 hours a day [12]. Insulin resistance was determined using the Homeostatic Model Assessment for Insulin Resistance (HOMA-IR) value with a cutoff value of $>3.54[14]$.

Blood samples were taken at 08.00-09.00 after the subject fasted for 12 hours through the median cubital vein. Ten ccs of blood were taken for examination of blood sugar, HDL, and triglycerides.

\subsection{Statistical analysis}

The data were processed using Microsoft Excel 2010 and SPSS version 21. The normality test of the data used the Kolmogorov-Smirnov test. Analysis of the relationship data using unpaired T-test, Mann-Whitney, and Chi-square. 


\section{RESULTS}

3.1 Characteristic of patients

The essential characteristics of the research subjects included demographic data (age, gender, education), anthropometric examination, blood pressure, sleep duration, and laboratory tests (table 1). One hundred twenty-four obese adolescents with metabolic syndrome aged 13-18 years, 84 (67.7\%) boys and 40 (32.2\%) girls.

$\underline{\text { Table 1. Characteristic of Subject }}$

\begin{tabular}{|c|c|}
\hline Variable & $\begin{array}{l}\mathrm{N}(\%) \\
\mathrm{x} \pm \mathrm{SD}\end{array}$ \\
\hline \multicolumn{2}{|l|}{ Demography } \\
\hline \multicolumn{2}{|l|}{ Age } \\
\hline $13-15$ y.o & $62(50)$ \\
\hline $16-18$ y.o & $62(50)$ \\
\hline \multicolumn{2}{|l|}{ Gender } \\
\hline Boys & $84(67,7)$ \\
\hline Girls & $40(32,2)$ \\
\hline \multicolumn{2}{|l|}{ Education } \\
\hline Junior high school & $54(43,5)$ \\
\hline Senior high school & $70(56,5)$ \\
\hline \multicolumn{2}{|l|}{ Anthropometry } \\
\hline Body weight (kg) & $89,05 \pm 15,38$ \\
\hline Height $(\mathrm{m})$ & $1,62 \pm 0,08$ \\
\hline Body mass index $\left(\mathrm{kg} / \mathrm{m}^{2}\right)$ & $33,80 \pm 4,72$ \\
\hline Waist circumference $(\mathrm{cm})$ & $101,85 \pm 10,00$ \\
\hline \multicolumn{2}{|l|}{ Blood Pressure } \\
\hline abnormal & $111(89,5)$ \\
\hline Normal & $13(10,5)$ \\
\hline \multicolumn{2}{|l|}{ Laboratory } \\
\hline Fasting blood glucose (mg/dL) & $86,44 \pm 7,86$ \\
\hline Cholesterol (mg/dL) & $173,69 \pm 34,46$ \\
\hline $\mathrm{LDL}(\mathrm{mg} / \mathrm{dL})$ & $114,78 \pm 27,33$ \\
\hline HDL (mg/dL) & $38,48 \pm 6,16$ \\
\hline Triglyceride (mg/dL) & $135,54 \pm 60,84$ \\
\hline HOMA-IR & $5,59 \pm 3,22$ \\
\hline
\end{tabular}




\subsection{Comparison between variable and sleep duration}

Comparison test between variables and sleep duration using unpaired T-test analysis, Mann-Whitney and Chisquare with a significance value of $\mathrm{p}<0.05$ (table 2 ). The comparison test showed that the 16-18 year group had more short sleep duration than the 13-15 age group, which was statistically significant.

Table 2. Comparison between variable and sleep duration

\begin{tabular}{|c|c|c|c|}
\hline & $\begin{array}{c}\text { Sleep duration }<8 \mathrm{~h} \\
\mathrm{n}(\%)=84 \\
(\mathrm{x} \pm \mathrm{SD})\end{array}$ & $\begin{array}{c}\text { Sleep duration } \geq 8 \mathrm{~h} \\
\mathrm{n}(\%)=40 \\
(\mathrm{x} \pm \mathrm{SD})\end{array}$ & p-value \\
\hline \multicolumn{4}{|l|}{ Demography } \\
\hline \multicolumn{4}{|l|}{ Age } \\
\hline $13-15$ y.o & $36(29,0)$ & $26(21)$ & $0,021 *$ \\
\hline $16-18$ у.о & $48(38,7)$ & $14(11,3)$ & \\
\hline \multicolumn{4}{|l|}{ Gender } \\
\hline Boys & $59(47,6)$ & $25(20,2)$ & $0,389 *$ \\
\hline Girls & $25(20,2)$ & $15(12,1)$ & \\
\hline \multicolumn{4}{|l|}{ Anthropometry } \\
\hline Body weight (kg) & $90,07 \pm 15.26$ & $86,91 \pm 15,60$ & $0,287 * *$ \\
\hline Height (m) & $1,62 \pm 0,08$ & $1,62 \pm 0,07$ & $0.814 * * *$ \\
\hline Body mass index $\left(\mathrm{kg} / \mathrm{m}^{2}\right)$ & $34,20 \pm 4,60$ & $32,95 \pm 4,92$ & $0,169 * *$ \\
\hline Waist circumference $(\mathrm{cm})$ & $102,26 \pm 10,44$ & $100,99 \pm 9,06$ & $0,51 * *$ \\
\hline \multicolumn{4}{|l|}{ Blood pressure } \\
\hline Abnormal & $78(70,3)$ & $33(29,7)$ & $0,780 *$ \\
\hline Normal & $6(46,2)$ & $7(53,8)$ & \\
\hline \multicolumn{4}{|l|}{ Laboratory } \\
\hline Fasting blood glucose (mg/dL) & $86,86 \pm 8,20$ & $85,57 \pm 7,11$ & $0,185^{*} * *$ \\
\hline Cholesterol (mg/dL) & $174,05 \pm 36,07$ & $172,93 \pm 31,21$ & $0,866^{* *}$ \\
\hline LDL (mg/dL) & $116,52 \pm 25,09$ & $111,13 \pm 31,56$ & $0,306^{* *}$ \\
\hline HDL (mg/dL) & $38,25 \pm 6,08$ & $38,98 \pm 6,387$ & $0,461 * * *$ \\
\hline Triglyceride (mg/dL) & $134,35 \pm 61,90$ & $138,05 \pm 59,23$ & $0,753 * *$ \\
\hline
\end{tabular}

3.3 Association between short sleep duration and insulin resistance

The relationship between short sleep duration and insulin resistance in both age groups gave statistically significant results. In the 13-15year age group, the PR value was 1.78 with a phi coefficient of 0.43 , which means that obese adolescents with metabolic syndrome in the 13-15year age group who experience short sleep can experience insulin resistance incidence of 1.78 times compared to adequate sleep with the strength of the association. Currently. The 1618year age group has a PR value of 2.9 with a phi coefficient of 0.478 , which means that obese adolescents with metabolic syndrome in the 16-18year age group who experience short sleep can experience insulin resistance events of 2.9 times compared to getting enough sleep with moderate association strength. The 16-18year age group has a higher PR value than the 13-15year age group. 
Table 3. Association between short sleep duration and insulin resistance

\begin{tabular}{lccccc}
\hline Variable & $\begin{array}{c}\text { Insulin } \\
\text { resistance }\end{array}$ & $\begin{array}{c}\text { Non-insulin } \\
\text { resistance }\end{array}$ & PR & $\begin{array}{c}\text { coefficient } \\
\text { Phi }\end{array}$ & P-value \\
\hline & & $13-15$ y.o & & $0.001^{*}$ \\
\hline Sleep duration $<8 \mathrm{~h}$ & $32(51.6 \%)$ & $4(6.5 \%)$ & 1.78 & 0.430 & \\
Sleep duration $\geq 8 \mathrm{~h}$ & $13(21 \%)$ & $13(21 \%)$ & $16-18 \mathrm{y} .0$ & & $<0.001^{*}$ \\
\hline Sleep duration $<8 \mathrm{~h}$ & $39(62.9 \%)$ & $9(14.5 \%)$ & 2.90 & 0.478 & \\
Sleep duration $\geq 8 \mathrm{~h}$ & $4(6.5 \%)$ & $10(16.1 \%)$ & & & \\
\hline
\end{tabular}

*p $<0.05$ Significant

\section{DISCUSSIONS}

There was a significant difference between sleep duration and age group; namely, short sleep duration was more commonly found in the 16-18year age group. Similar results were also found in several previous studies $[15,16,17,18]$. Older age is associated with a more challenging level of education and is followed by more school assignments and activities and broader social interactions, all of which will reduce sleep duration $[15,16]$. This research in China also mentions that biological/psychosocial conditions, environmental influences, school schedules, and daily activities affect sleep duration in adolescents [16].

Short sleep duration is thought to have a direct impact on glucose homeostasis and insulin sensitivity. The mechanisms that cause impaired insulin sensitivity and glucose metabolism in short sleep duration are complex and challenging to explain. Short sleep duration or lack of sleep will increase circulating cortisol and induce sympathetic activity and increase catecholamines. In addition, sleep restriction has been reported to decrease TSH and testosterone levels, disrupt growth hormone secretion patterns, and increase levels of proinflammatory cytokines. These complex endocrine changes are thought to contribute to impaired insulin signaling in peripheral tissues, leading to insulin resistance [19].

Besides affecting the regulation of the hormones Leptin and Ghrelin, short sleep duration can also increase sympathetic nerve activity, produce proinflammatory cytokines, increase cortisol and insulin antagonists. All the effects caused by lack of sleep will lead to insulin resistance [20].

This study showed a moderate relationship between short sleep duration and insulin resistance in both groups, with a higher PR value in the 16-18year group. Several previous studies also gave the same result; namely, short sleep duration was associated with the incidence of insulin resistance, as indicated by an increase in the HOMA-IR value [1,8,21,22]. Studies by Korostovtseva et al. and Rawat et al. mention that short sleep duration can lead to impaired glucose tolerance and glucose metabolism $[23,24]$.

Several physiological conditions increase insulin resistance, namely puberty, pregnancy, and old age. Puberty, defined as a period of human development, physical growth, and sexual maturity, is characterized by a decrease in insulin sensitivity and a compensatory increase in insulin secretion. Other changes associated with puberty include increased insulin growth factor-1 (IGF-1), GH, and sex hormones. Several stages of pubertal maturation are associated with increased insulin secretion and the HOMA-IR index, and it is generally expected that these changes will return to average values by the end of puberty. In children with obesity, resistance increases significantly at puberty [25].

Increasing age is considered to affect the Association, environment, school schedule, daily activities, and psychosocial conditions of adolescents, and all of these will affect a person's sleep duration $[15,16]$. Reduced sleep duration will affect 
insulin resistance in all adolescents, but the impact will be more significant in adolescents with obesity [25]. This is because obese adolescents have much adipose tissue, which is the pathogenesis of insulin resistance by releasing metabolites, hormones, and adipocytokines that can affect insulin activity. Adipocytes produce unesterified fatty acids, which inhibit carbohydrate metabolism through substrate competition and impaired intracellular insulin signaling [26,27].

The limitation of this study was that the researchers also did not check the genetic factors of each subject and did not take into account the physical activity of each subject so that this condition could be a research bias.

\section{CONCLUSION}

Short sleep duration has a moderate association with insulin resistance. Older adolescents have a higher chance of developing insulin resistance due to lack of sleep.

\section{ACKNOWLEDGEMENT}

None.

\section{FINANCIAL SUPPORT}

This research received no specific grant from any funding agency, commercial or not-for-profit sectors.

\section{CONFLICT OF INTEREST}

None.

\section{ETHICAL STANDARD}

This study obtained permission from the ethics committee. Ethical approval was obtained the Research and Ethics Scientific Committee at the faculty of medicine Universitas Airlangga, Surabaya, Indonesia (141/EC/KEPK/FKUA/2020). All procedures performed were in accordance with the ethical standards and with the 1964 Helsinki Declaration and its later amendments. Before the subject recruitment, an explanation of general research information was carried out to the subjects and their parents for getting their consent.

\section{REFFERENCE}

1. Lee J, Choi YS, Jeong YJ, Lee J, Kim JH, Kim SH, et al. Poor-quality sleep is associated with metabolic syndrome in Korean adults. Tohoku J Exp Med. 2013;231:281-91.

2. Seo SH, Shim YS. Association sf Sleep duration with obesity and cardiometabolic risk factors in children and adolescents: a population-based study. Sci Rep. 2019;9:1-10.

3. Chen X, Beydoun MA, Wang Y. Is sleep duration associated with childhood obesity? a systematic review and meta-analysis. Obesity. 2008;16:265-74.

4. Kumar S, Kumar H. Sleep hygiene and diabetes. J Pakistan Med Assoc. 2016;66:1665-8.

5. Paruthi S, Brooks LJ, D'Ambrosio C, Hall WA, Kotagal S, Lloyd RM, et al. Recommended amount of sleep for pediatric populations: a consensus statement of the American academy of sleep medicine. J Clin Sleep Med. 2016;12:785-6.

6. Chaput JP, Dutil C. Lack of sleep as a contributor to obesity in adolescents: impacts on eating and activity behaviors. Int J Behav Nutr Phys Act. 2016;13:1-9.

7. Hemati Z, Mozafarian N, Heshmat R, Ahadi Z, Motlagh ME, Ziaodini H, et al. Association of sleep duration with metabolic syndrome and its components in children and adolescents; a propensity score-matched analysis: The CASPIAN-V study. Diabetol Metab Syndr. 2018;10:1-9.

8. Matthews KA, Dahl RE, Owens JF, Lee L, Hall M. Sleep duration and insulin resistance in healthy black and white adolescents. Sleep. 2012;35:1353-8.

9. Nogueira-de-Almeida CA, de Mello ED. Different criteria for the definition of insulin resistance and its relation with dyslipidemia in overweight and obese children and adolescents. Pediatr Gastroenterol Hepatol Nutr. 2018;21:59-67. 
10. Alberti G, Zimmet P, Kaufman F, Tajima N, Silink M, Arslanian S, et al. The IDF consensus definition of the metabolic syndrome in children and asolescents. Alberti G, Zimmet P, Kaufman F, Tajima N, Silink M, Arslanian S, et al., editors. IDF Communication. Brussels: Pediatric Diabetes; 2007. 1-24 p.

11. Simon SL, Behn CD, Cree-Green M, Kaar JL, Pyle L, Hawkins SMM, et al. Too Late and Not Enough: School Year Sleep Duration, Timing, and Circadian Misalignment Are Associated with Reduced Insulin Sensitivity in Adolescents with Overweight/Obesity. J Pediatr. 2018;11:1-8.

12. Widjaja NA, Prihaningtyas RA, Irawan R, Hanindita MH. Sleep duration and metabolic syndrome. Int J Occup Med Environ Health. 2021;16:33-7.

13. Sung V, Hons M, Beebe DW, Vandyke R, Fenchel MC, Crimmins NA, et al. Does sleep duration predict metabolic risk in obese adolescents attending tertiary services? a cross-sectional study. Sleep. 2011;34:891-8.

14. Kim JW, Park SH, Kim Y, Im M, Han H-S. The cutoff values of indirect indices for measuring insulin resistance for metabolic syndrome in Korean children and adolescents. Ann Pediatr Endocrinol Metab. 2016;21:143-8.

15. Cao M, Zhu Y, Li X, Chen Y, Ma J, Jing J. Gender-dependent association between sleep duration and overweight incidence in Chinese school children: a national follow-up study. BMC Public Health. 2018;18:1-9.

16. Chen T, Wu Z, Shen Z, Zhang J, Shen X, Li S. Sleep duration in Chinese adolescents: biological, environmental, and behavioral predictors. Sleep Med. 2014;15:1345-53.

17. Amaral O, Pereira C, Veiga N, Coutinho E, Chaves C. Gender and age differences in the sleep habits : a cross-sectional study in adolescents. Aten Primaria. 2016;48:178-82.

18. Mathew G, Varghese AD, Benjamin AI. A comparative study assessing sleep duration and associated factors among adolescents studying in different types of schools in an urban area of Kerala, India. Indian J Community Med. 2019 Oct;44:103 .

19. Mesarwi O, Polak J, Jun J, Polotsky VY. Sleep disorders and the development of insulin resistance and obesity. Endocrinol Metab Clin North Am. 2014;42:1-18.

20. Tobaldini E, Fiorelli EM, Solbiati M, Costantino G, Nobili L, Montano N. Short sleep duration and cardiometabolic risk: from pathophysiology to clinical evidence. Nat Rev Cardiol. 2019;16:213-24.

21. Flint J, Kothare S V, Zihlif M, Suarez E, Adams R, Legido A, et al. Association between inadequate sleep and insulin resistance in obese children. J Pediatr. 2007;150:364-9.

22. Sayin FK, Buyukinan M. Sleep duration and media time have a major impact on insulin resistance and metabolic risk factors in obese children and adolescents. Child Obes. 2016;12:272-8.

23. Korostovtseva L, Alieva A, Rotar O, Bochkarev M, Boyarinova M, Sviryaev Y, et al. Sleep duration, lipid profile and insulin resistance: potential role of lipoprotein(a). Int J Mol Sci. 2020;21:1-13.

24. Rawat A, Gangwar AK, Tiwari S, Kant S, Garg RK, Singh PK. Sleep quality and insulin resistance in adolescent subjects with different circadian preference : a cross-sectional study. J Fam Med Prim Care. 2019;6:2502-5.

25. Cardenas-Vargas E, Nava JA, Garza-Veloz I, Torres-Castañeda MC, Galván-Tejada CE, Cid-Baez MA, et al. The Influence of Obesity on Puberty and Insulin Resistance in Mexican Children. Int J Endocrinol. 2018;2:1-10.

26. Chiarelli F, Marcovecchio ML. Insulin resistance and obesity in childhood. Eur J Endocrinol. 2008;159:67-74.

27. Matsuzawa Y. White adipose tissue and cardiovascular disease. Best Pract Res Clin Endocrinol Metab. 2005;19:637-47. 